RURAL WOMEN'S PRACTICES FOR RATIONALIZING HOME ENERGY CONSUMPTION AND THEIR KNOWLEDGE ABOUT ADVANTAGES AND DISADVANTAGES OF USING TRADITIONAL AND NEW RESOURCES OF ENERGY IN SOME VILLAGES IN BEHIRA GOVERNORATE

Hassieb, Hayam M. A.

Agriculture Extension and Rural Development Research Institute, ARC.

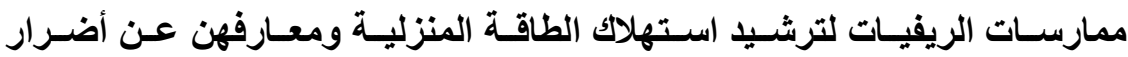

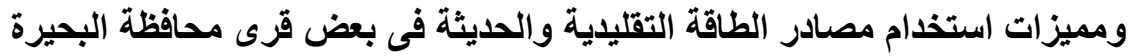

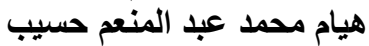
معهد بحوث الإششاد الزراعى والتنمية الريفية ـ مركز البحوث الزراعية

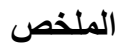

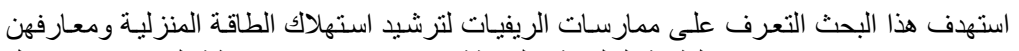

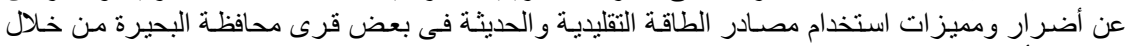

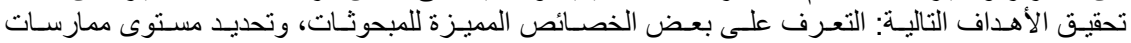

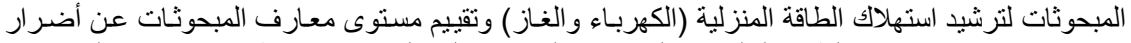

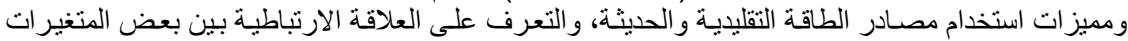

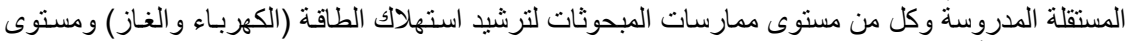

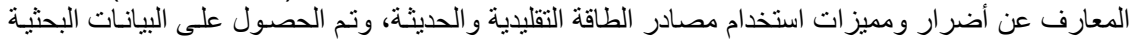

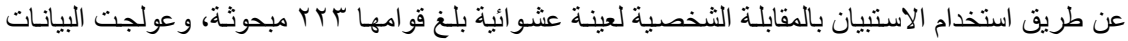

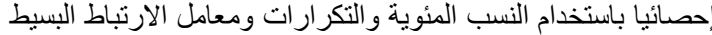
وقث أسفرت الاراسة عن النغام النتائج التالية:

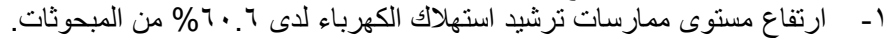

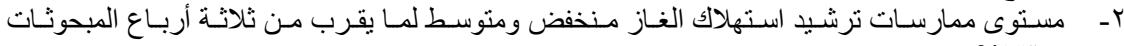
.\%रr.o

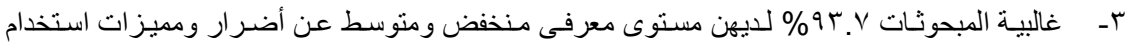
مصادر الطاقة التقليدية و الحديثة.

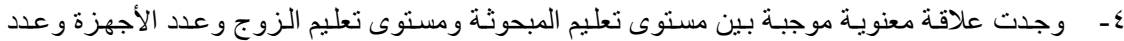

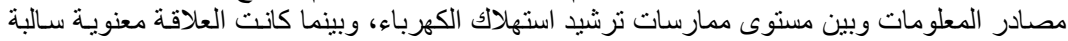

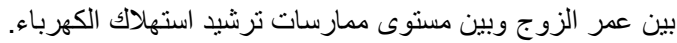

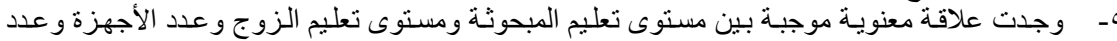

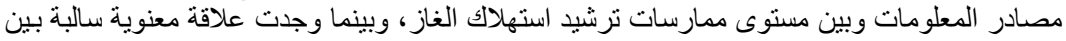

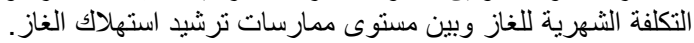

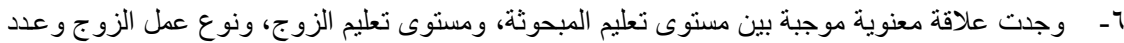

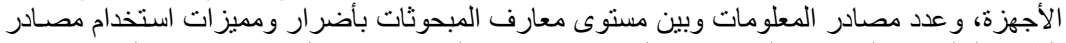

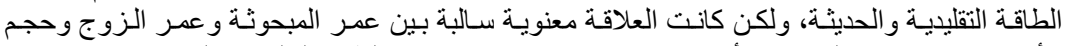

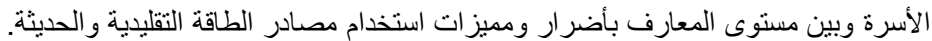


Hassieb, Hayam M. A.

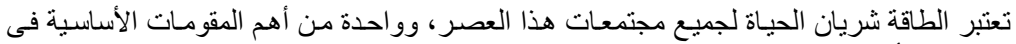

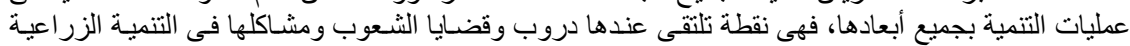

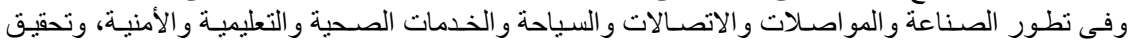

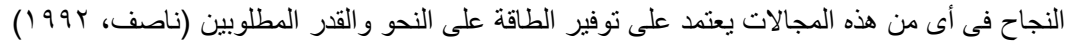

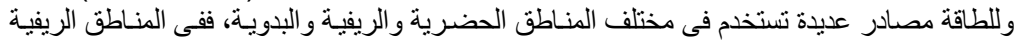

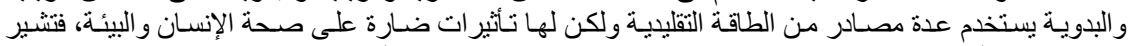

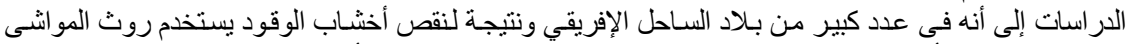

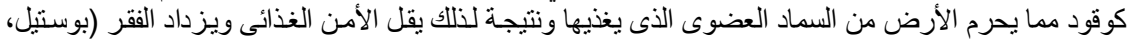

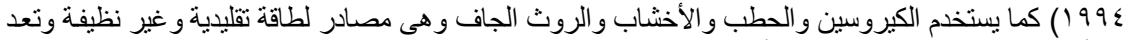

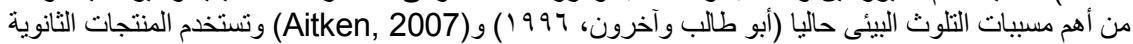

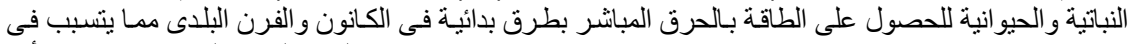

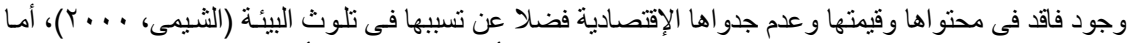

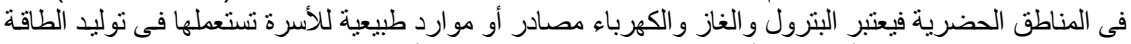

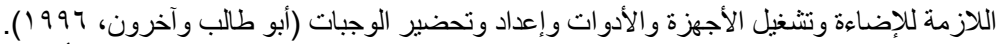

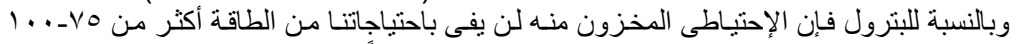

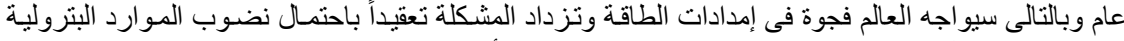

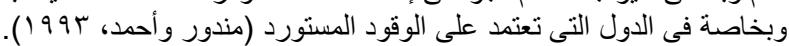

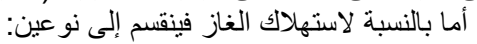

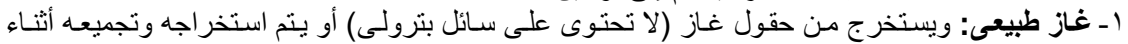

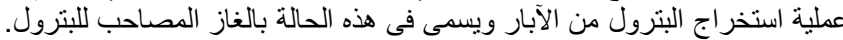

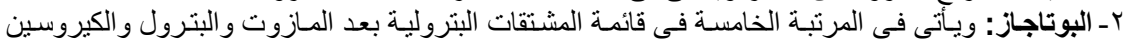

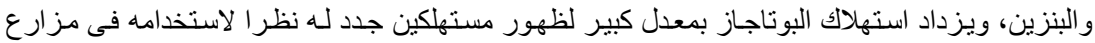

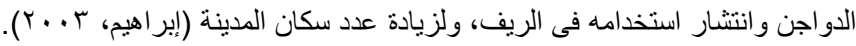

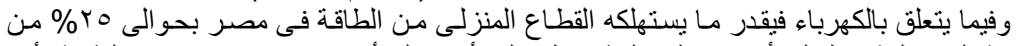

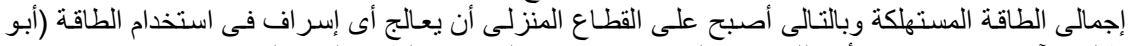

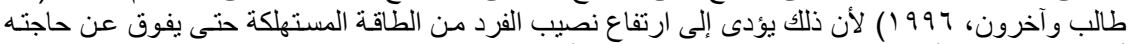

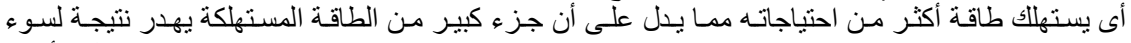

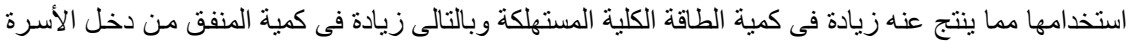

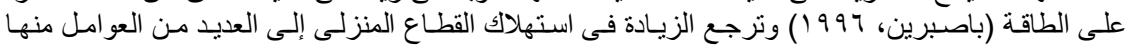

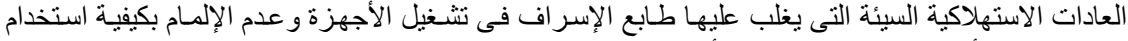

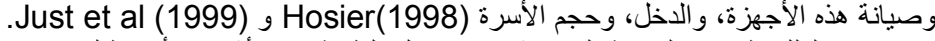

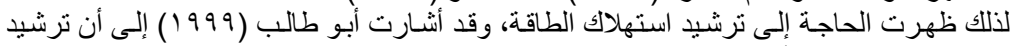

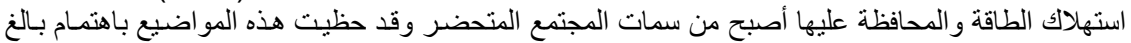

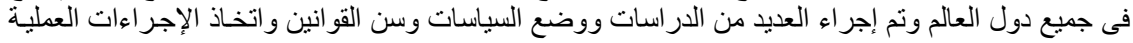

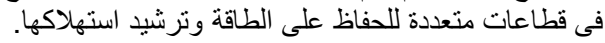

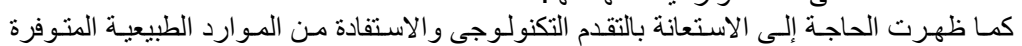

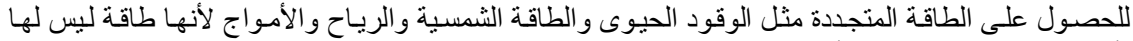

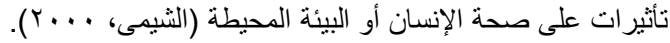

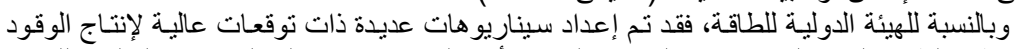

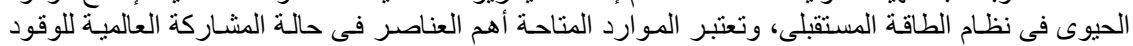

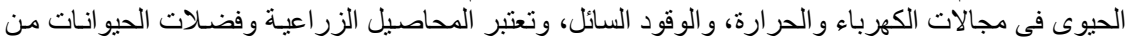

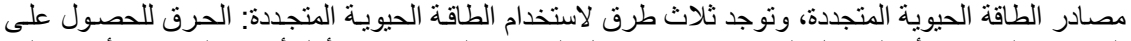

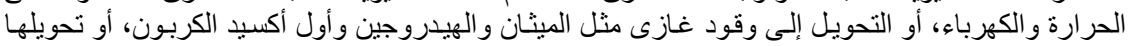

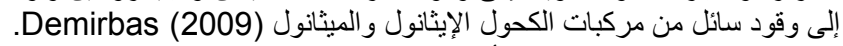

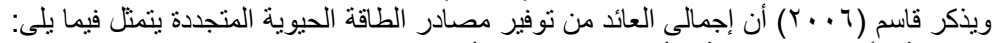

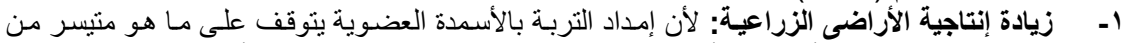

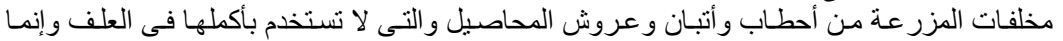

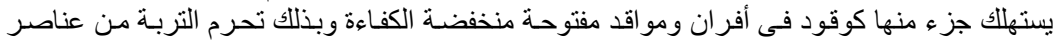




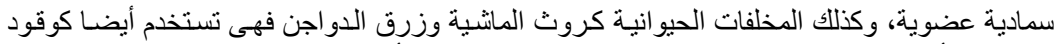

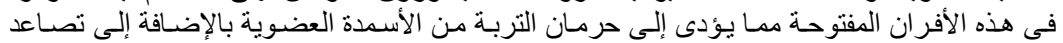

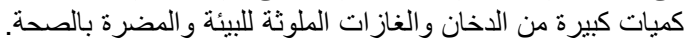

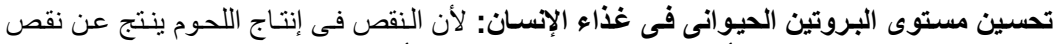

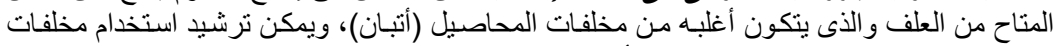

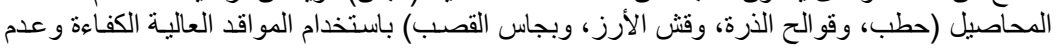

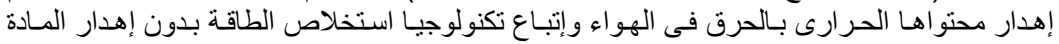

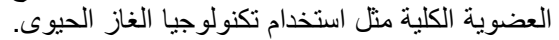

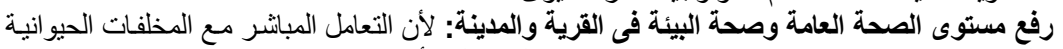

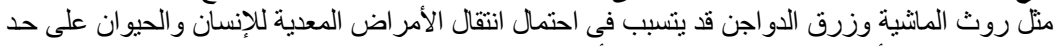

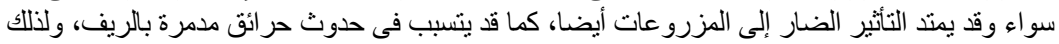

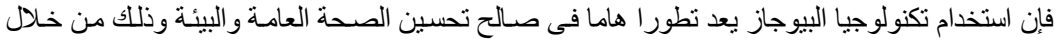

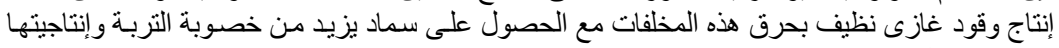

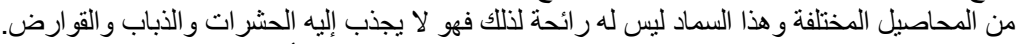

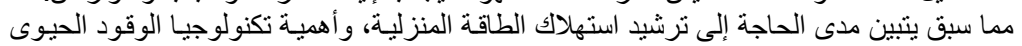

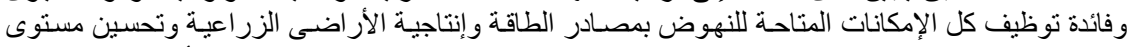

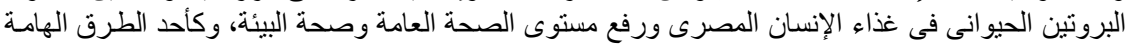
لترشيد استهلاك الطاقة.

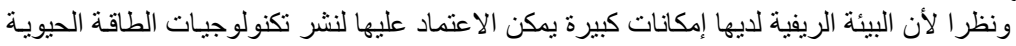

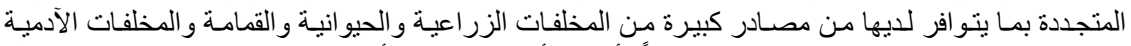

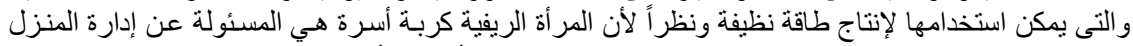

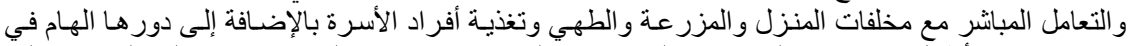

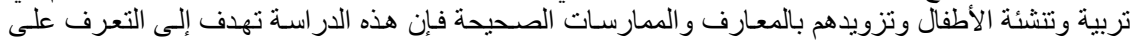

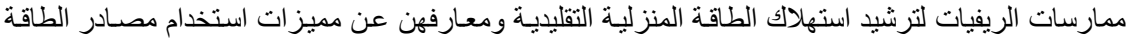

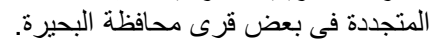

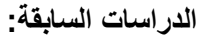

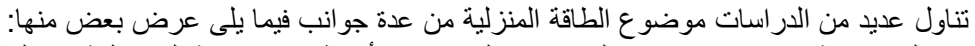

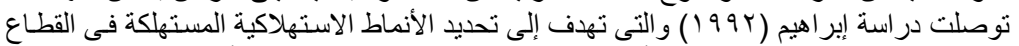

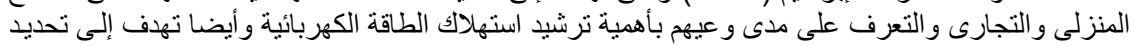

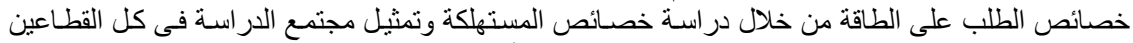

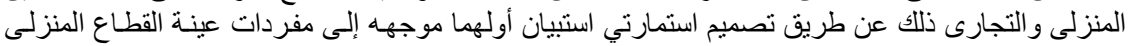

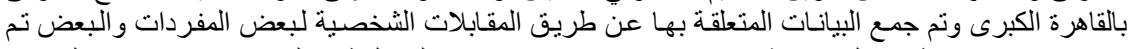

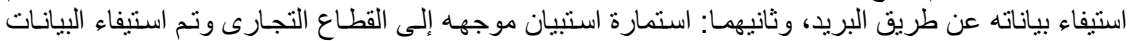

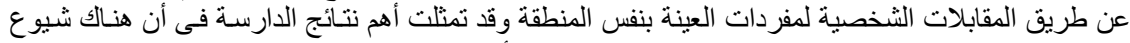

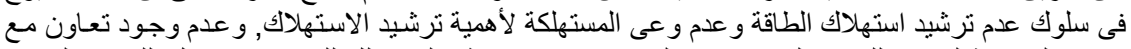

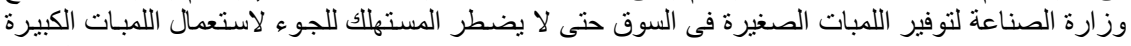

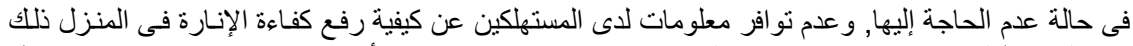

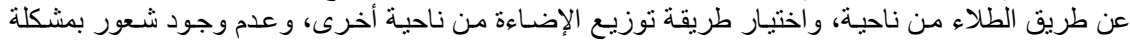

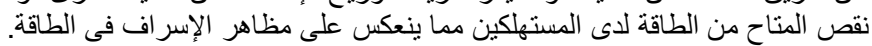

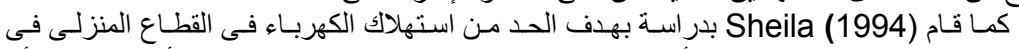

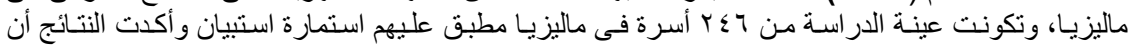

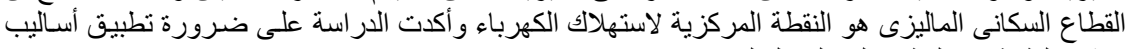
ترشيد الطاقة فى القطاع المنزلى المى الماليزى.

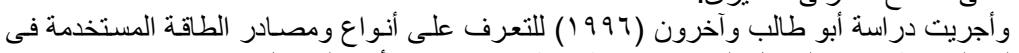

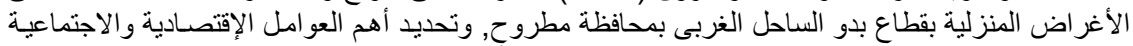

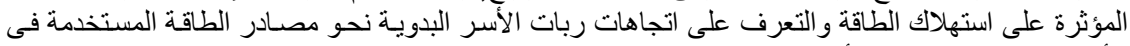

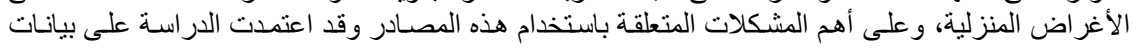


Hassieb, Hayam M. A.

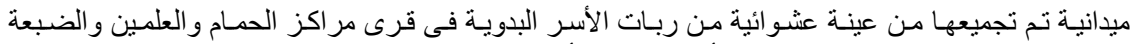

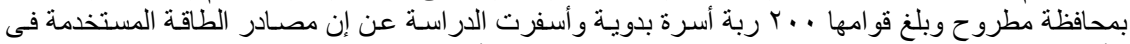

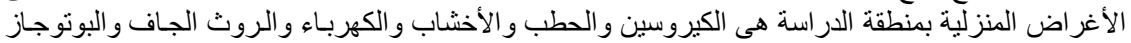

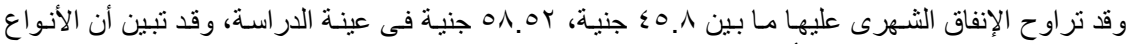

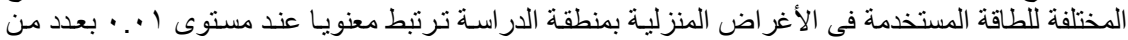

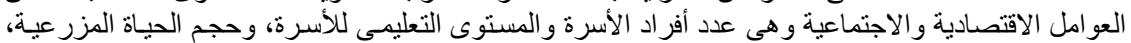

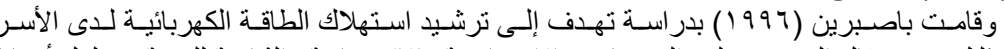
و إجمالى الإنفاق الإستهلاكى.

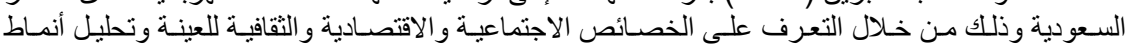

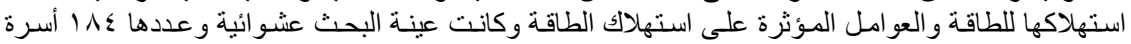

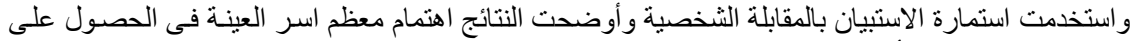

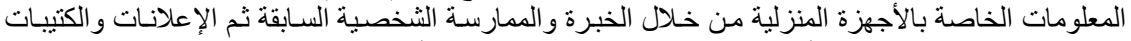

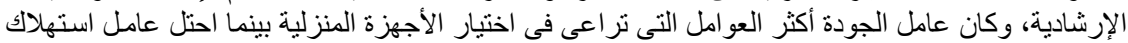

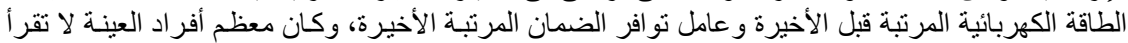

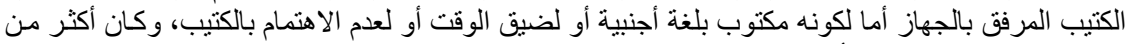

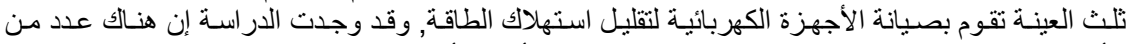

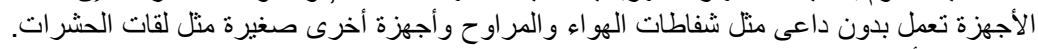

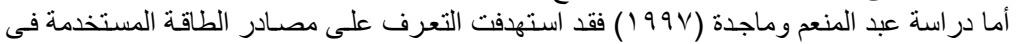

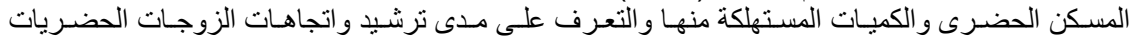

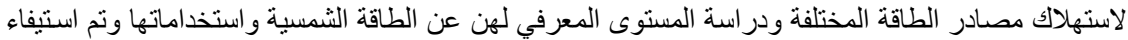

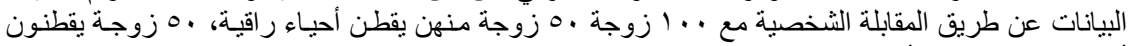
أحياء شعبية وتتركز أهم النتائج فيما يلى الثع:

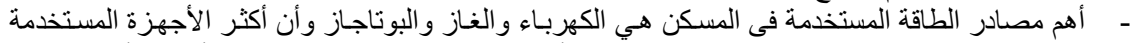

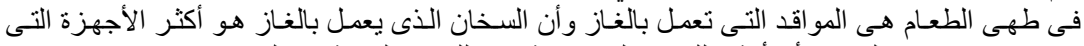

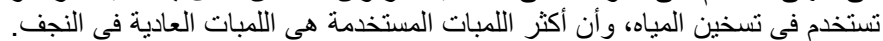

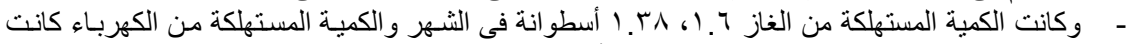

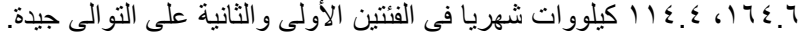

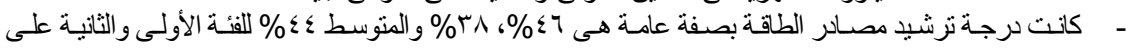
الثو الىى.

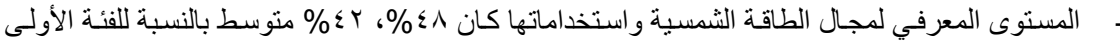
و والثانية على التو التى التى. - وقد ارتبط استهلاك الأسرة للكهرباء و الغاز بعلاقة طردية قوية مع تعليم ربة الأسرة.

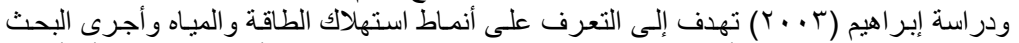

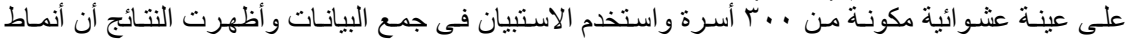

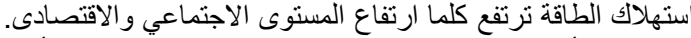

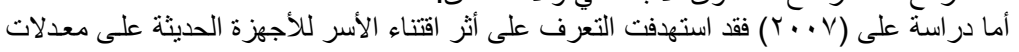

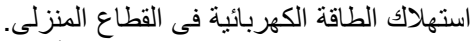

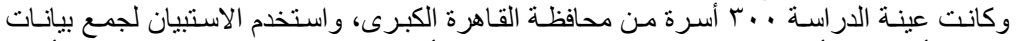

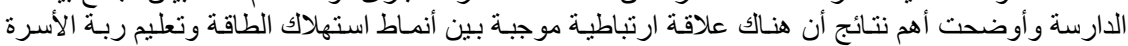

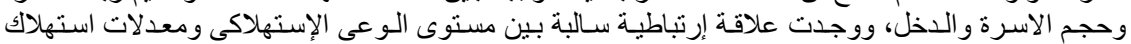
الطاقة الكهربائية.

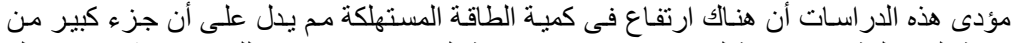

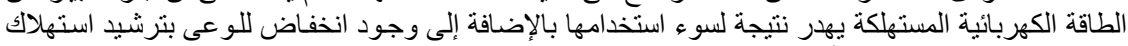

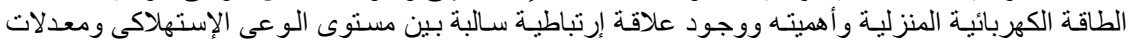

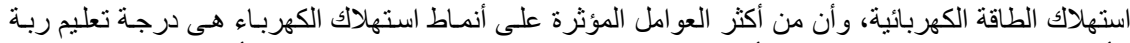

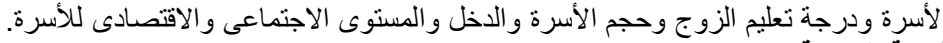




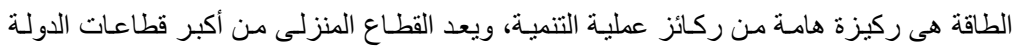

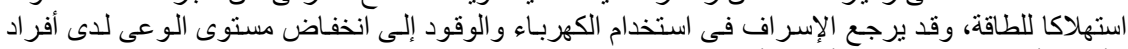

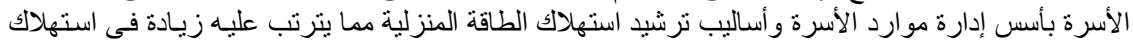

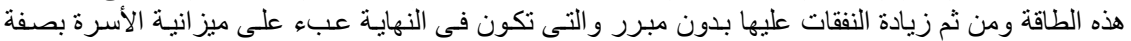

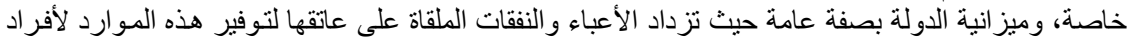

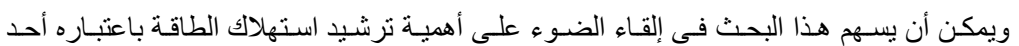
المجتمع.

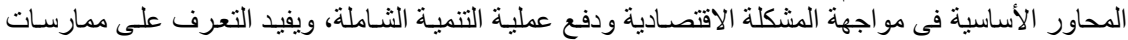

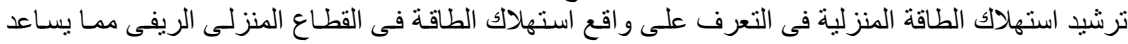

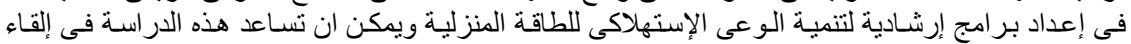

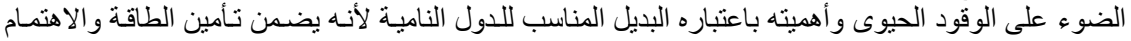
بالبيئة وتطوير القطاع الريفى.

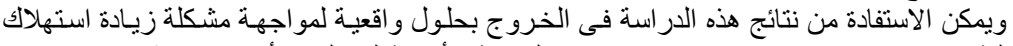

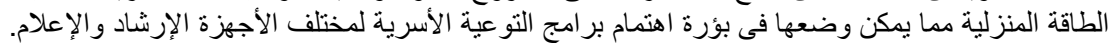
أهداف الإرسة المنة

تهـف هذه الدراسـة إلى التعرف على ممارسـات الريفيـات لترشيد استهلاك الطاقـة المنزليـة

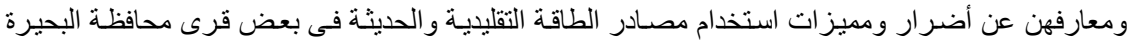
وذللك من خلال تحقيق الأهداف التالية:

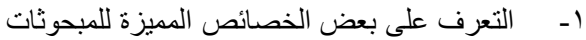

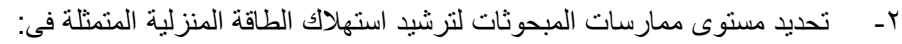

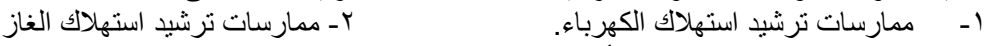

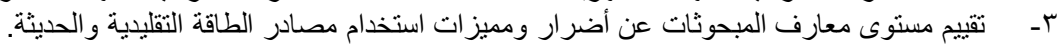

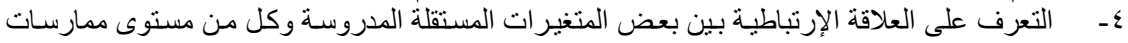

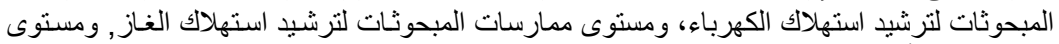
المعارف عن أضرار ومميزات استخدام مصادر الطاقة التقليدية والحديثة الكيثة.

تحقيقا لهدف الدراسة الرابع نم صياغة الفروض البحثية التالية

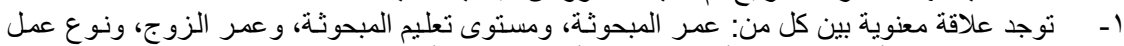

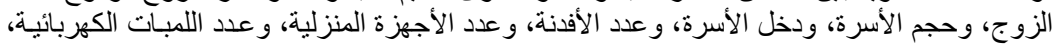

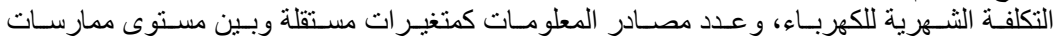

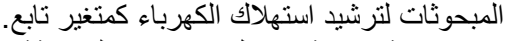

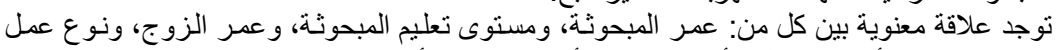

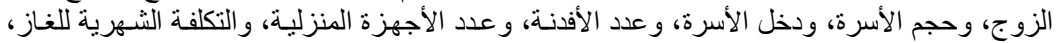

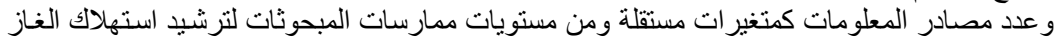
كمتغير تابع.

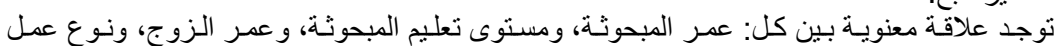

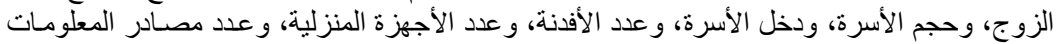

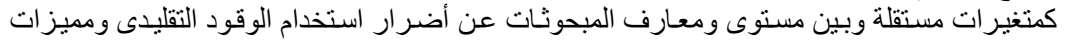
مصادر حديثة للطاقة كمتغير تابع. وسوف نختبر هذه الفروض البحئ تُبة في صورنها الصفرية.

\section{الطريقة البحثية}

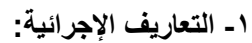
أ- ممارسات ترشيد استهلاك الطانية الطاقة المنزلية: بقصد بها: • ممارسات ترشيد استهلاك الكهرباء: 
Hassieb, Hayam M. A.

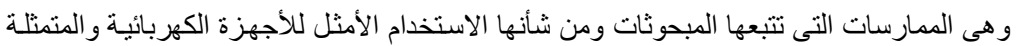

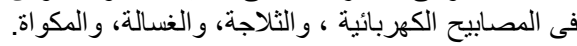

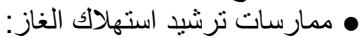

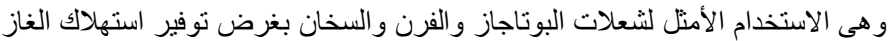

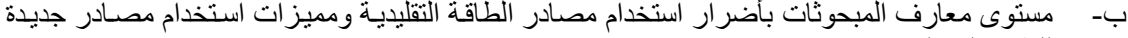

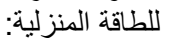

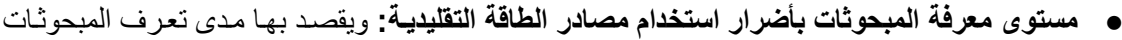

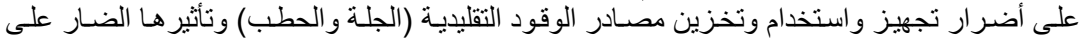
صحة الإنسان وصحة بيئة المسكن.

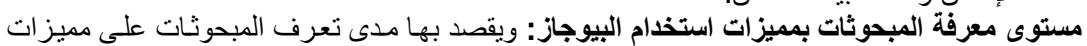

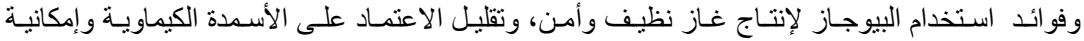

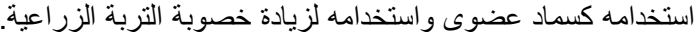

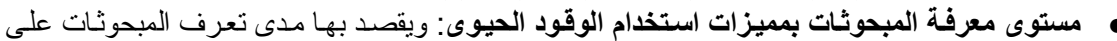

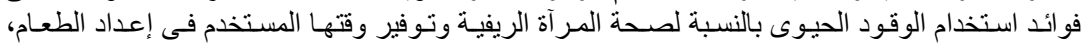

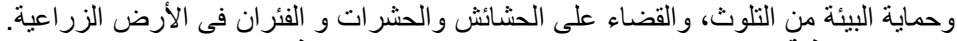

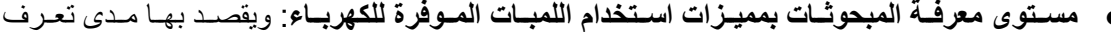

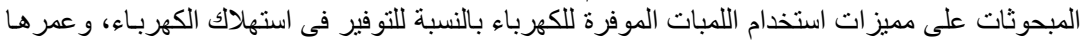

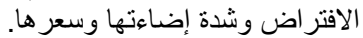

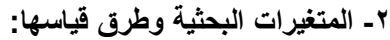

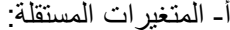

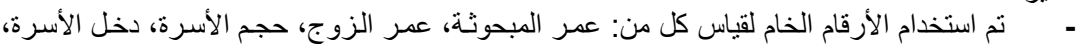

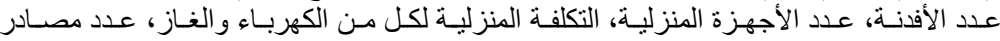
معلومات المبحوثة. معنة

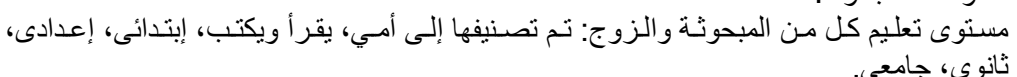

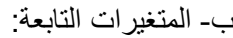
أولا: ممارسات ترشيد استهلاك الطاقة: وتم دراستها من خلال

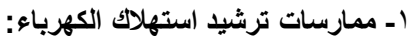

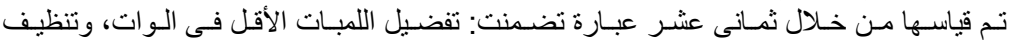

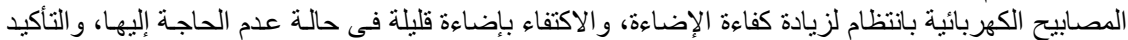

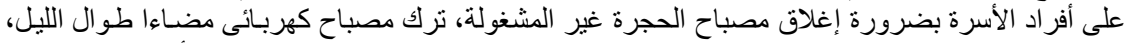

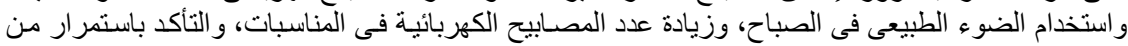

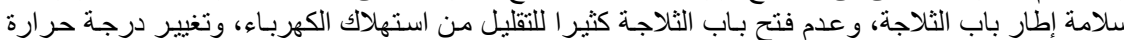

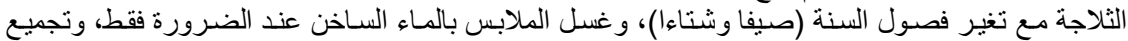

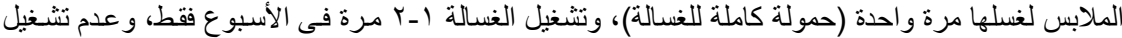

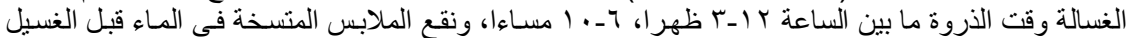

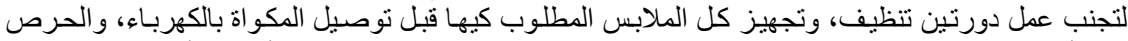

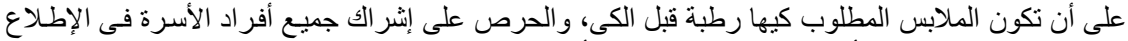

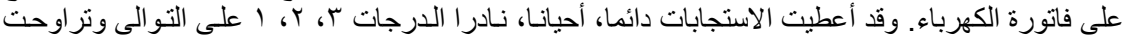

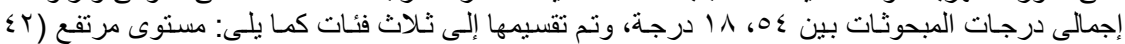

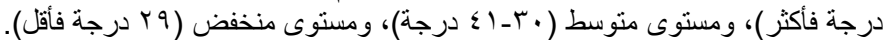
r- ممارسات ترشيد استهلاك الغاز:

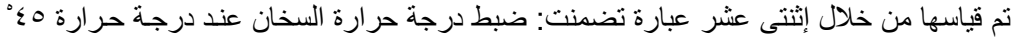

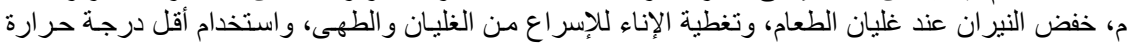

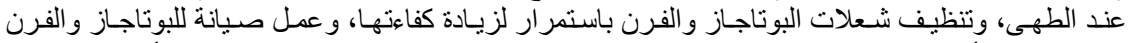

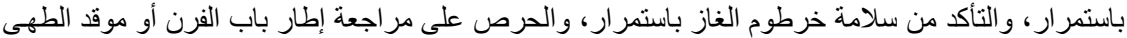

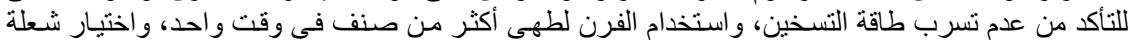


الموقد المناسبة لحجم الإنـاء حتى لا تسمح بفقدان طاقـة خـار ج الإنـاء، وإطفاء الفرن قبل تمـام التسوية لتقليل

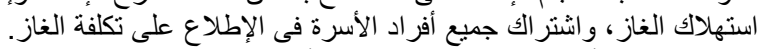

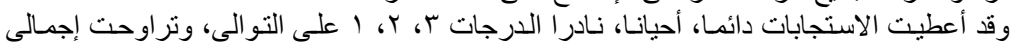

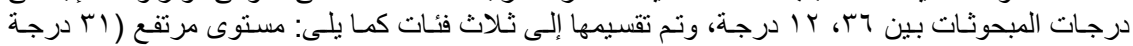

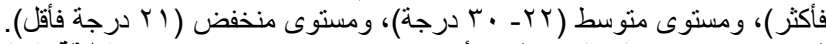

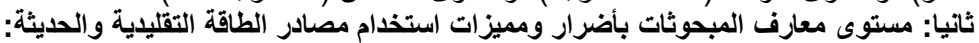

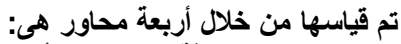

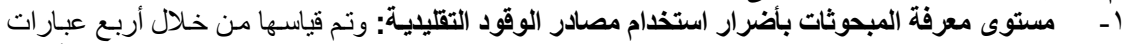

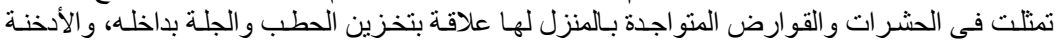

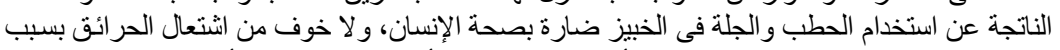

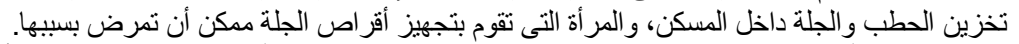

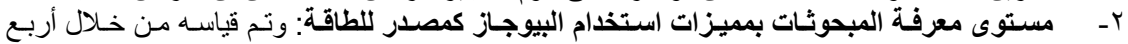

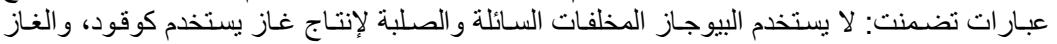

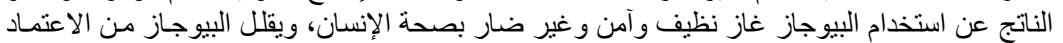

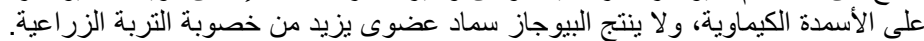

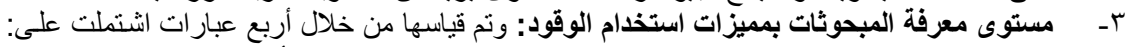

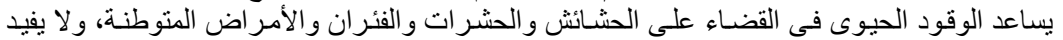

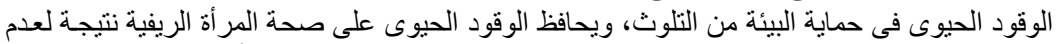

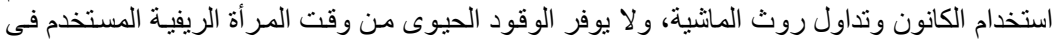

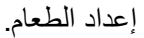

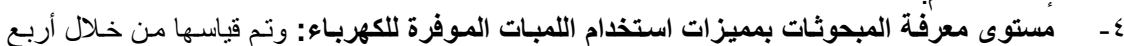

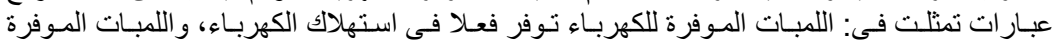

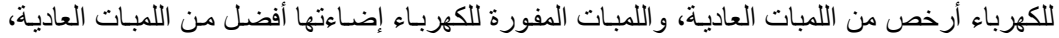

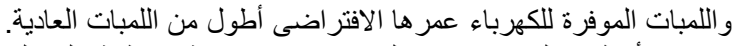

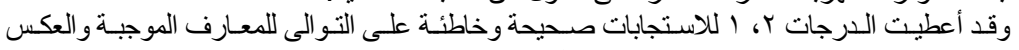

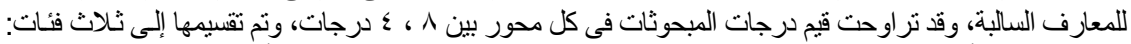

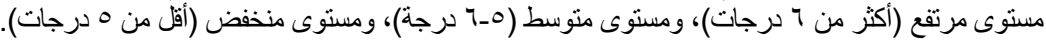

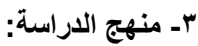

تعتمد هذه الدر اسة على المنهج الوصفى التحليلى و الذى يعتمد على دراسـة الظـاهرة كما توجد في

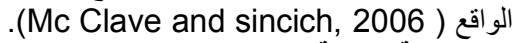

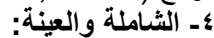

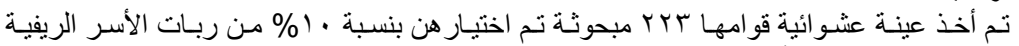

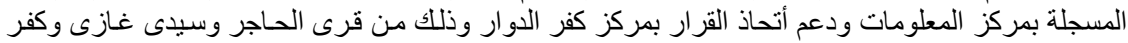

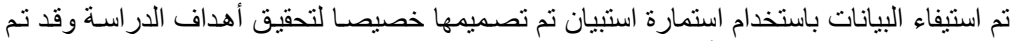

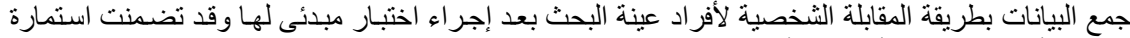

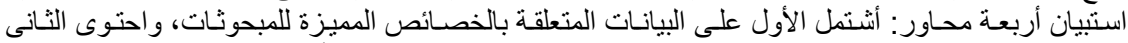

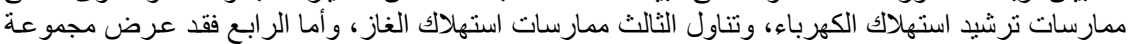

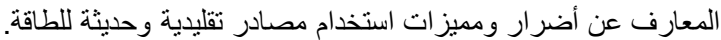

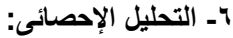

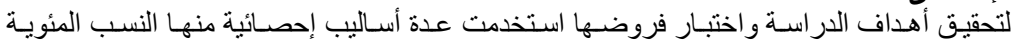

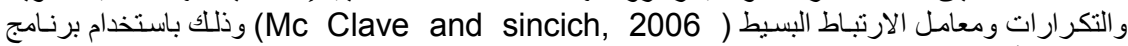
الحاسب الألى S.P.S.S وتخزين وتحليل البيل البيانات.

نتائج الدراسة

807 
Hassieb, Hayam M. A.

أولا الخصائص المميزة للمبحوثات:

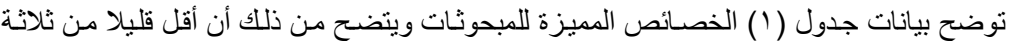

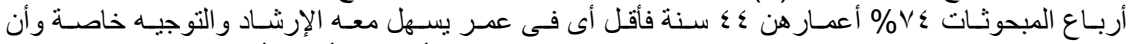

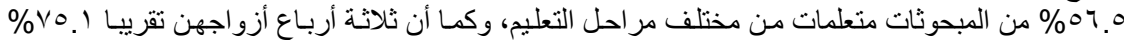

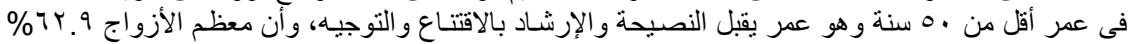

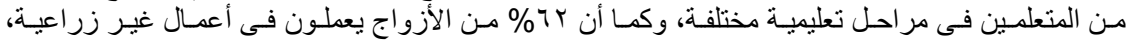

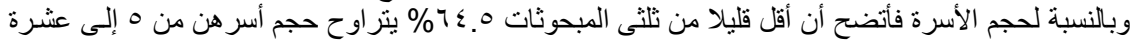

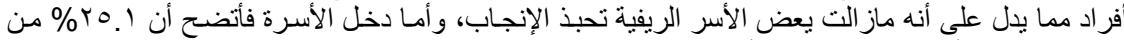

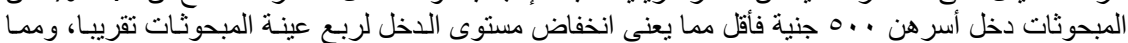

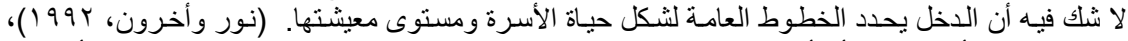

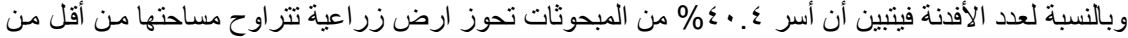

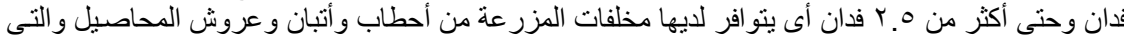

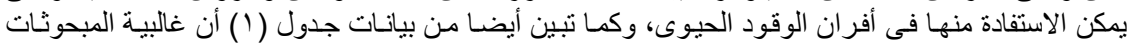

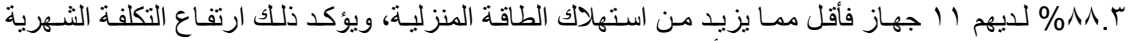

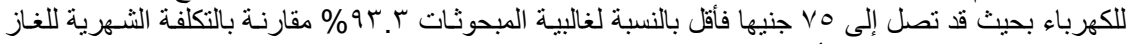

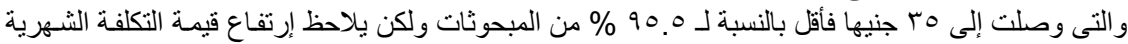

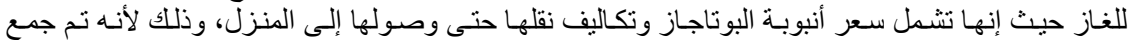

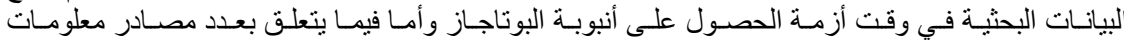

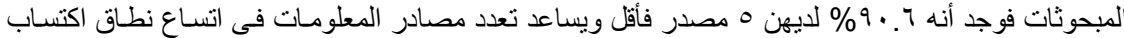
المبحوثات للمعلومات و والمعارف اله الجديدة.

جدول (1): توزيع المبحوثات وفقا لخصائصهن المميزة.

\begin{tabular}{|c|c|c|c|c|c|}
\hline$\%$ & عدد & الخصائص & $\%$ & عدد & الخصائص \\
\hline & & |ٓ- آ- حجم الأسرة & & & |- عمر المبحوثة \\
\hline ro.0 & $V V$ & 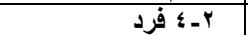 & $r \wedge . \gamma$ & $T \leq$ & 9q بنة \\
\hline 07.0 & 1 T4 & هـ 9 أفراد & $\leqslant 0 . r$ & 1.1 & . r- ؛ ؛ سنة \\
\hline \multirow[t]{2}{*}{ A. } & $r \cdot$ & • ا أفراد فأكثر & rY. & 01 & 0ـ سنة فأكثر \\
\hline & & | V| - دخل الأسرة & & & r- - مستوى تعليم المبحوثة \\
\hline Yo.1 & 07 & 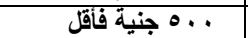 & $r \leqslant .0$ & VV & أمى - (أمي \\
\hline$\varepsilon \vee .1$ & 1.0 & |. 1... & 19.8 & $\varepsilon \varepsilon$ & يقرأ ويكتب \\
\hline \multirow[t]{2}{*}{ TV.A } & Tr & أكثر من . . . & $7 . r$ & $1 \leq$ & إبتدائي \\
\hline & & |م- عدد الأفدنة & $0 . \varepsilon$ & Ir & إعدادى \\
\hline 09.7 & Tr & لا يوجد & $r \Sigma . V$ & 00 & ثانوى \\
\hline$r \Sigma . r$ & $0 \leqslant$ & أفذان فأقل & $7 . r$ & $1 \leq$ & فوق متوسط \\
\hline$V .7$ & IV & & r.1 & V & جامعى \\
\hline \multirow[t]{2}{*}{1.0} & 19 & أكثر من •.ب فذان & & & " * عمر الزواج \\
\hline & & 9- عدد الأجهزة المنزلية & 51.9 & $7 \Lambda$ & مابنة فأقل \\
\hline $11 . \mathrm{V}$ & YY & V أجهزة فأقلّل & $\sum r . r$ & 94 & باس- •-0 سنة \\
\hline$V \cdot . \varepsilon$ & $10 \mathrm{~V}$ & 1-1 11 جهاز & $r \leqslant . q$ & or & ا 1 سنة فأكثر \\
\hline 18.9 & $\varepsilon \cdot$ & r r جهاز فأكثر & & & ـ- مستوى تعليم الزوج * \\
\hline
\end{tabular}




\begin{tabular}{|c|c|c|c|c|c|}
\hline & & • 1 - التكلفة الشهرية للكهرباء & rV. & 19 & أمى \\
\hline 07.0 & $1 Y 7$ & أقلّ من 0؛ جنية & $1 \leqslant .1$ & $r$. & يقرأ ويكتب \\
\hline rч.A & NT & ج & $\varepsilon .7$ & $1 \cdot$ & إبتدائى \\
\hline \multirow[t]{2}{*}{$7 . V$} & 10 & أكثر من • V جنية & $\varepsilon .7$ & $1 \cdot$ & إعدادى \\
\hline & & | 11 - التكلفة الثهرية للغاز & ro.r & $0 \leq$ & ثانوى \\
\hline 70. & $1 \leq 0$ & أقل من ·r جنيه & 7.1 & 14 & فوق متوسط \\
\hline$r \cdot .0$ & 71 & 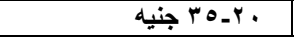 & 1. 1 & IV & جامعى \\
\hline \multirow[t]{2}{*}{$\varepsilon .0$} & $1 \cdot$ & أكثر من •r جنيه & & & •ـ عمل الزوج * \\
\hline & & | ا ـ - عدد مصادر المعلومات & rq.1 & $7 r$ & عمل ازراعى \\
\hline 01.7 & 110 & أقل من ب مصدر & Tr.O & 0. & عمل حرفى \\
\hline rq. & $\Lambda V$ & rــ مصدر & Tr.P. & $\leqslant 9$ & عمل مهنى \\
\hline \multirow[t]{3}{*}{$9 . \varepsilon$} & YI & أكثر من • مصدر & IT.V & TV & عمل تجارى \\
\hline & & & $r . \wedge$ & 7 & عل صناعى \\
\hline & & & 1.9 & 19 & لا يعمل \\
\hline
\end{tabular}

ثانياً: مستوى ممارسات ترشيد استهلاك الطاقة المنزلية: ا - مستوى ممارسات ترشيد استهلاتك الكهرباء

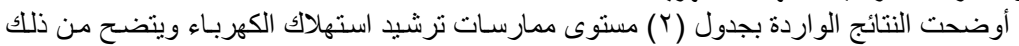

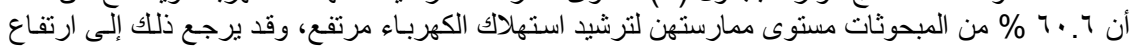

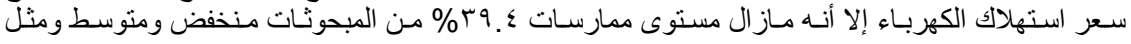

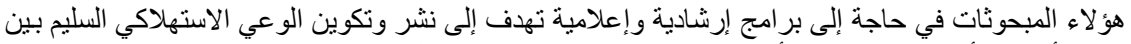

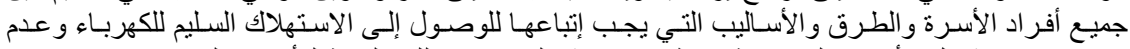

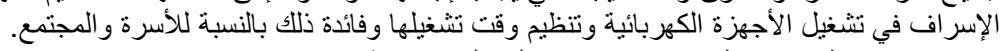

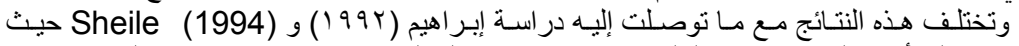

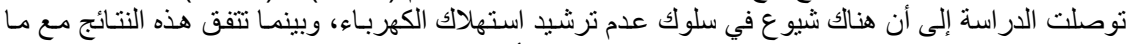

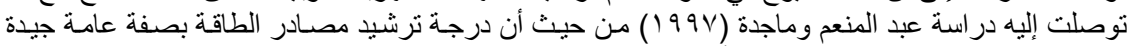

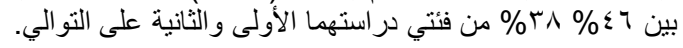

جدول (r) توزيع المبحوثات وفقاً لمستوى ممارساتهن لترشيد استهلاك الكهرباء

\begin{tabular}{|c|c|c|}
\hline$\%$ & عدد & مستوى الممارسات \\
\hline £.. & 9 & منخفض (9 ب درجة فأقل) \\
\hline ro. & 199 & متوسط (·ץ - إ درجة) \\
\hline 7.9 & 1 To & مرتفع (r؟ درجة فأكثر) \\
\hline $1 \ldots$ & KTr & الإجمالي \\
\hline
\end{tabular}

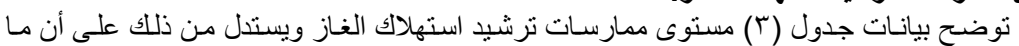

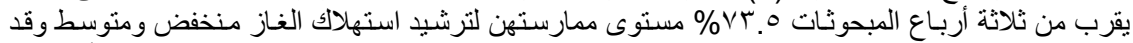

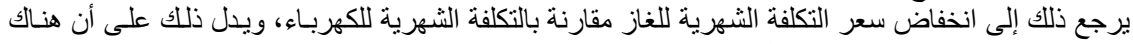

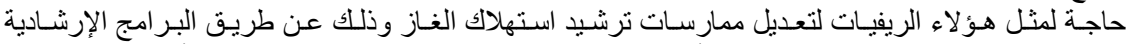

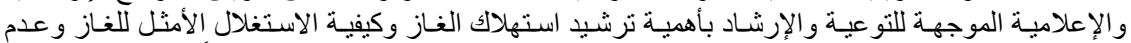

الإسر اف في استهلاك الغز وتقليل الفاقد بقدر المسنطاع و عدم الاستهانة به مهما كان ضئيلاً.

جدول (r) توزيع المبحوثات وفقاً لمستوى ممارساتهن لترشيد استهلاك الغاز

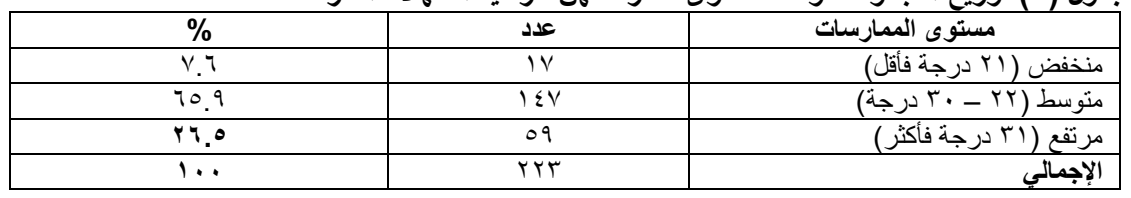


Hassieb, Hayam M. A.

ثالثاً: مستوى معارف المبحوثات عن أضرار ومميزات استخدام مصادر الطاقة التقليدية والحديثة:

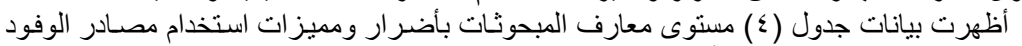

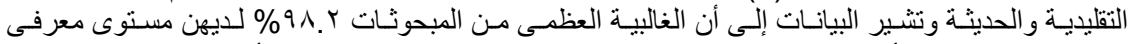

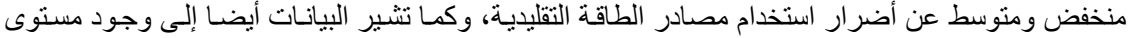

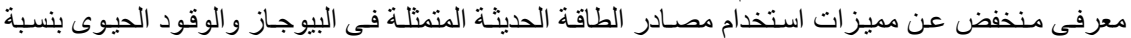

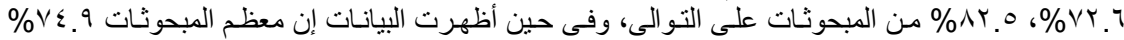

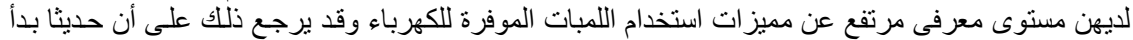

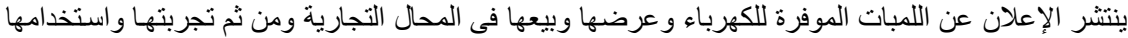

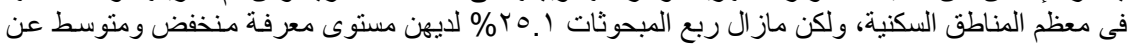
مميزات استخدام اللمبات الموفرة للكهرباء.

جدول (؛): توزيع المبحوثات وفقا لمستوى معارفهن بأضرار ومميزات استخدام مصادر الطاقة التقليدية والحليثة

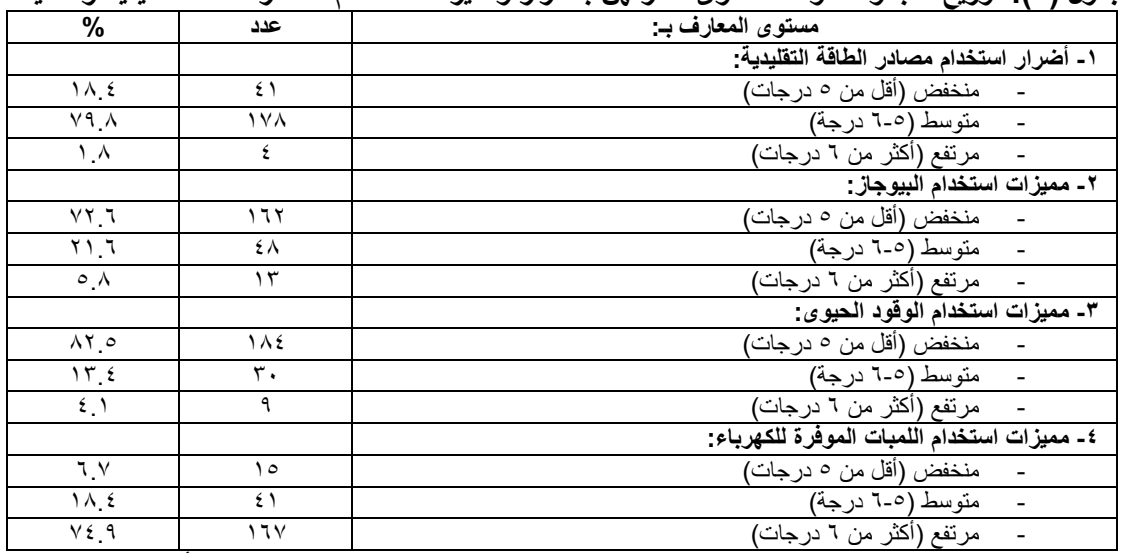

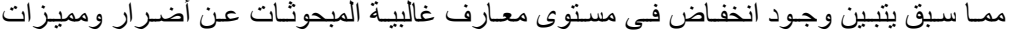

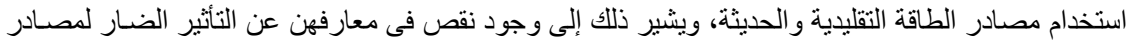

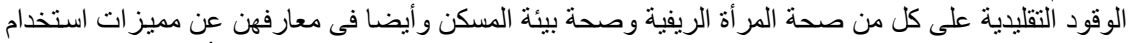

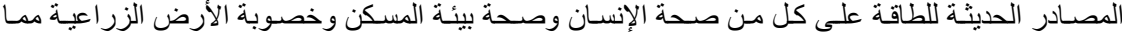
يتطلب بذلك المزيد من الجهود الإرشادية والإعلامية لزيادة معارف الريفيات فى هذه المجالات.

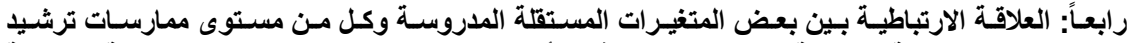

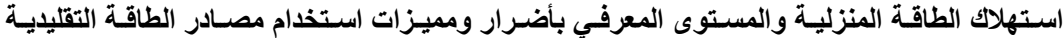

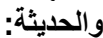

ا - مستوى ممارسات المبحوثات لترشيد استهلاك الطاقة المنزلية:

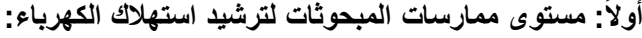

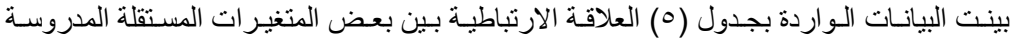

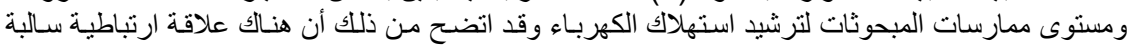

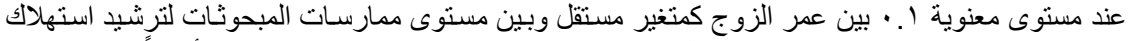

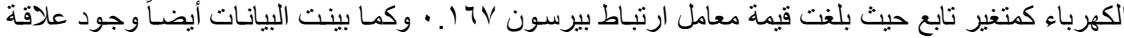

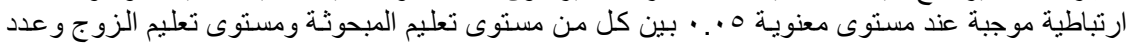

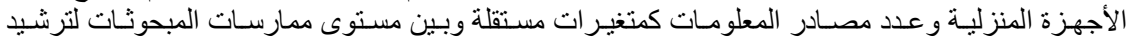

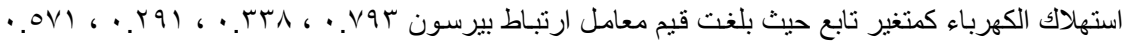
على التو الي. 


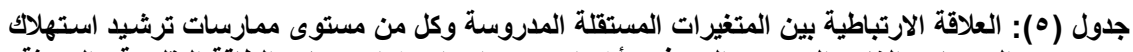

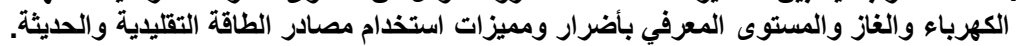

\begin{tabular}{|c|c|c|c|}
\hline استخدام مصادر الطاقية التقليدية والضرار وميزاتيثة & ترشيد استهلاك ممارسات الغاز & |مستوى ممارسنات ترشياء & المتغيرات المستقلة \\
\hline *..IV.- & $\because . r \Lambda_{-}$ & $. .119-$ & عمر المبحوثة \\
\hline${ }^{*} \cdot .1 \vee \wedge$ & ** . हाए & **. . Vq & مستوى تعليم المبحوثة \\
\hline$* * \cdot r \cdot 9-$ & $\because \cdots 7$ & $* .17 V_{-}$ & عمر الزوج \\
\hline ** $\cdot . \leqslant 1$. & **. YO. & ** $\cdot . r \mathrm{r}$ & مستوى تعليم الزوج \\
\hline$* * \cdot . Y \wedge \leq$ & $\because .19$ & $\because \cdot \leq 7$ & نوع عمل الزوج \\
\hline *. $. \Upsilon \wedge \cdot-$ & $.1 \cdots$ & $\because \cdot 1 \cdot-$ & حجم الأسرة \\
\hline$\because \cdot \leq \leqslant$ & $\because \cdot \leq r$ & $\because V Y$ & لخل الأسرة \\
\hline$\because .0 \leqslant-$ & ${ }^{*} \cdot .1 \leqslant 0$ & $\because \cdots Y$ & عدد الأفدنة \\
\hline **..rl. & **..Y.T & **. .191 & عدد الأجهزة المنزلية \\
\hline$\because \cdot Y I$ & $\because \wedge r$ & $\because .01$ & التنكلفة الشهرية للكهرباء \\
\hline$\because \cdot Y_{-}$ & *. .197 & .119 & التكلفة الثهرية للغاز \\
\hline${ }^{*} \cdot . I \mathrm{VV}$ & **..$\leq \leq r$ & **. $.0 \mathrm{VI}$ & عدد مصنادر المعلومات \\
\hline
\end{tabular}

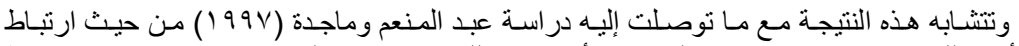

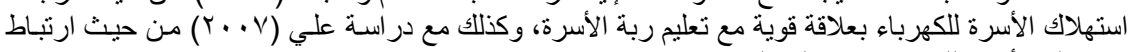
استهلاك الأسرة للكهرباء مع تعليم الزوباء بعلين.

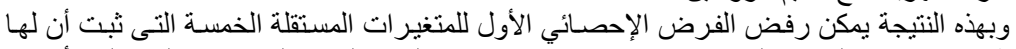

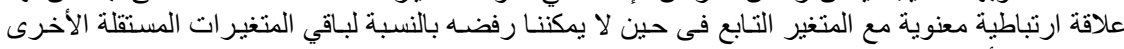

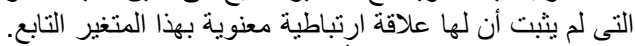

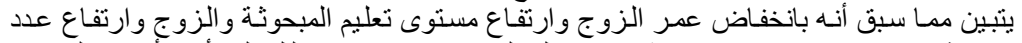

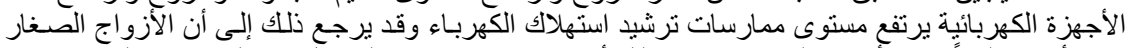

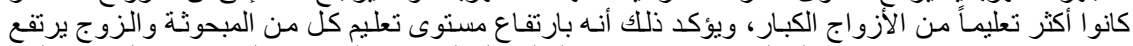

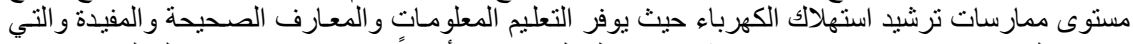

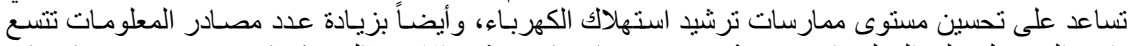

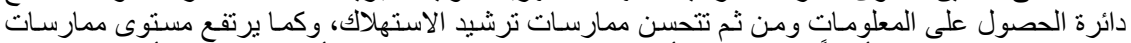

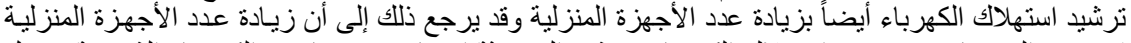

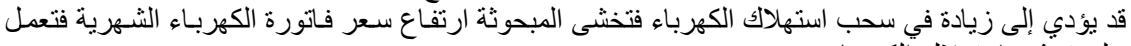

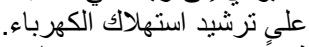

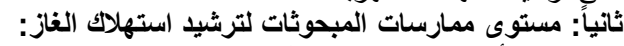

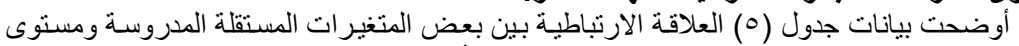

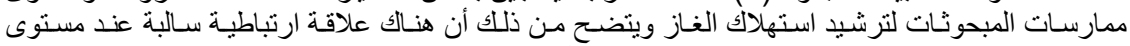

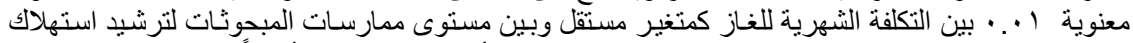

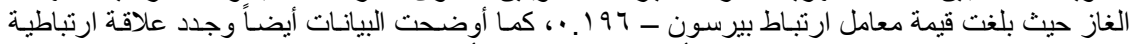

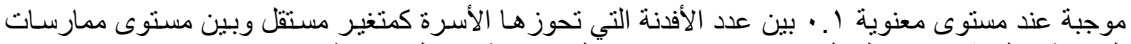

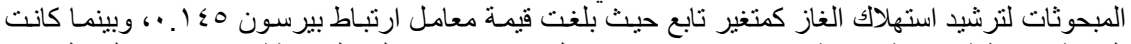

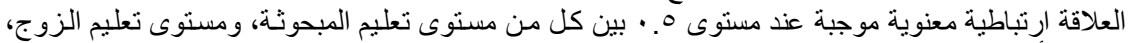

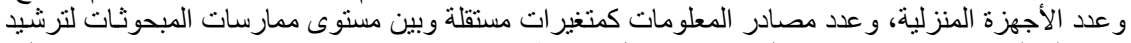

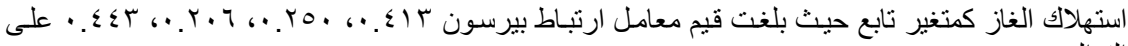
و هذه النتائج تتشابه مع مـا توصلت إليه در اسـة عبد المنعم وماجدة (99V ( ) ) في ارتبـاط استهلاك

التوالي. الأسرة للغاز بعلافة طردية قوية مع تعليم ربة الأسرة. 
Hassieb, Hayam M. A.

بهذه النتيجة يمكن رفض الفرض الإحصائي الثاني للمتغير ات المستقلة الستة التى ثبت أن لها علاقة

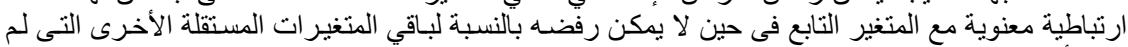

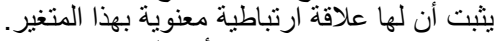

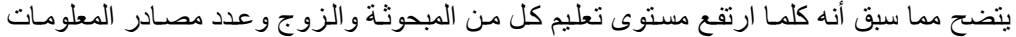

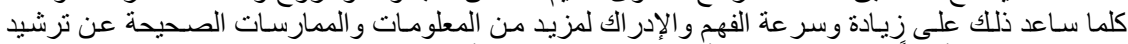

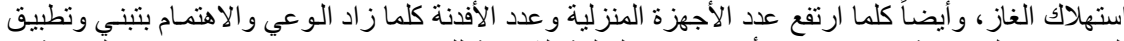

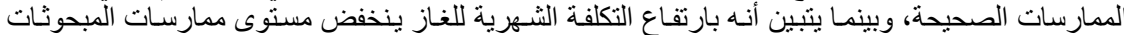

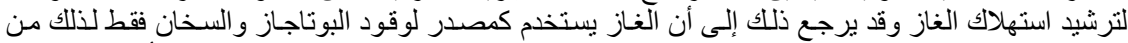

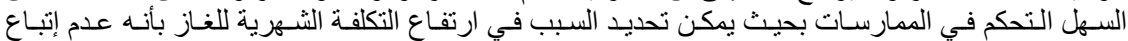
الممارسات الصحيحة لترشيد استهاتلاك الغاز

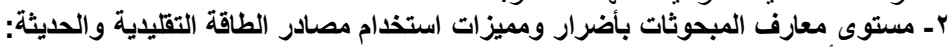

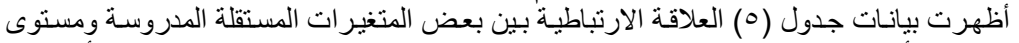

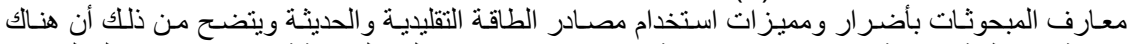

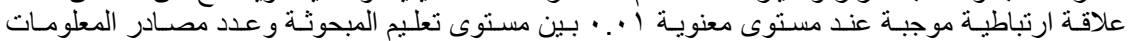

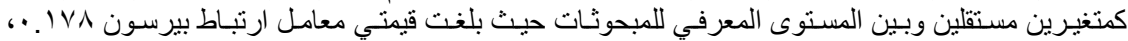

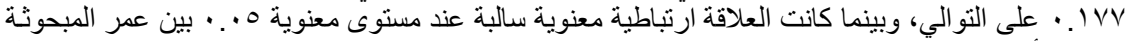

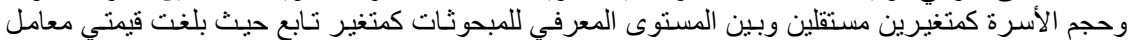

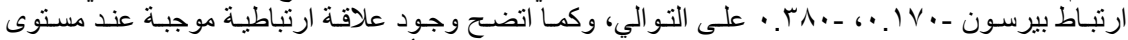

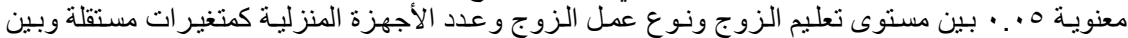

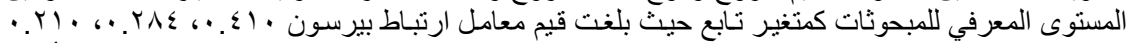

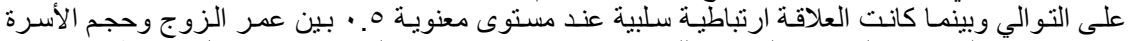
كمتغيرين منتقلين وبين المستوى المعرفي للمبحوثات كمتغير تابع حيث بلغت قيمتي معامل المبن ارتباط بيرسون $\therefore r \lambda \cdot r . r \cdot 9$

وبهذه النتيجة يمكن رفض الفرض الإحصائي الثالث للمتغير ات المستقلة الثمانية النى ثبت أن لها

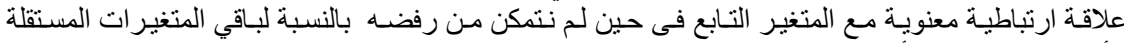

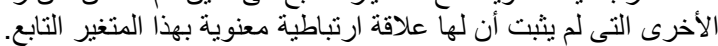

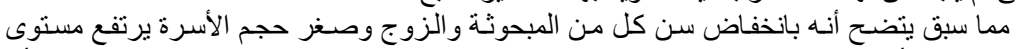

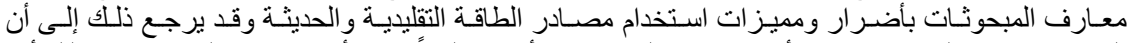

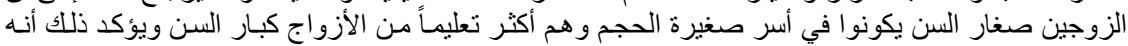

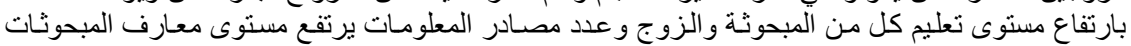

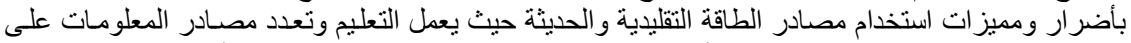

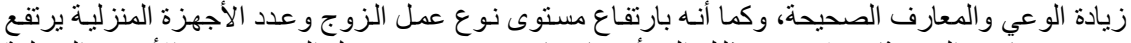

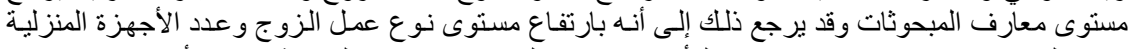

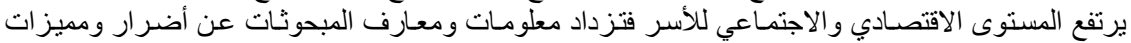
استخدام مصادر الطاقة التقليدية والحديثة.

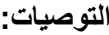

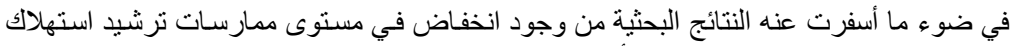

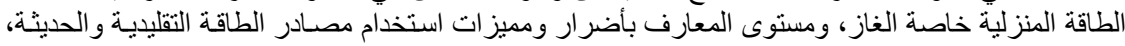

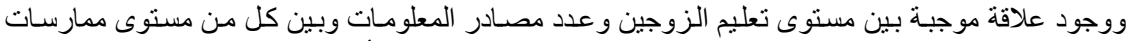

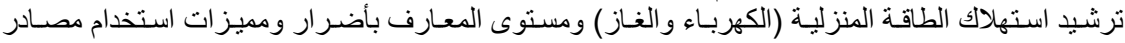

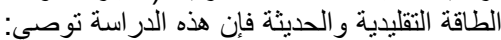

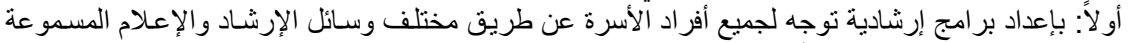

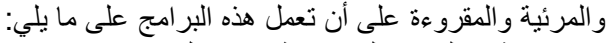

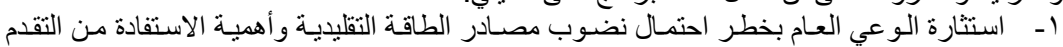

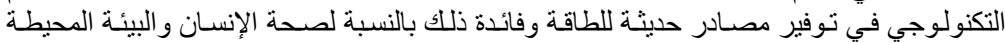

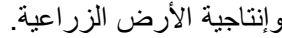
r- القيام بحملات إرشادية دورية منظمة لترشيد استهلاك الطاقة المنزلية. 


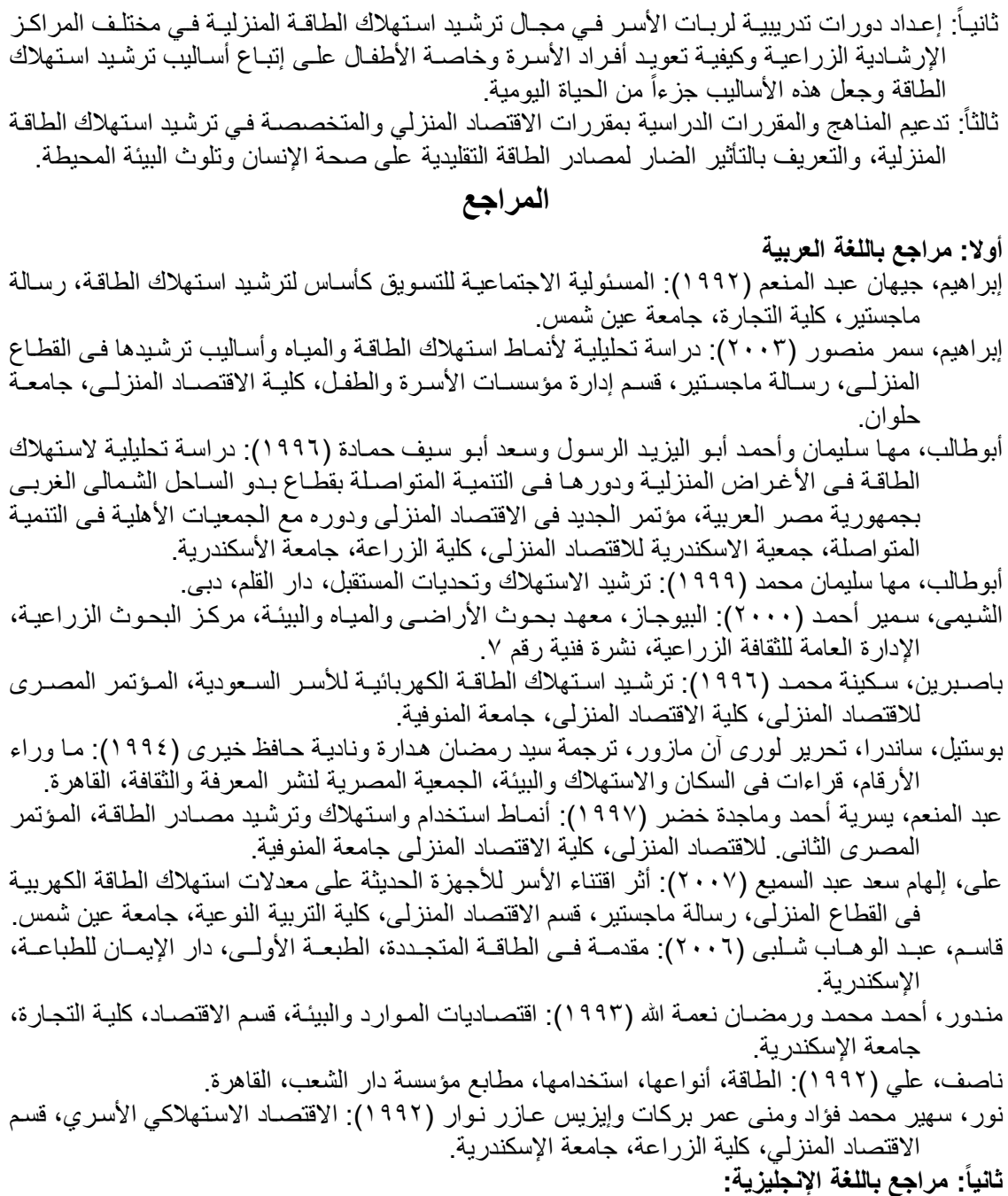

Aitken, R. (2007): Household energy use, a comparison of household energy consumption and expenditure across three provinces, journal of energy in Southern Africa vol. (18) No.1.

Demirbas, A. (2009): Biofuels, Securing the Plant Future Energy Needs, springer-verlag, London Limited.

Hoseier, R., H., and Dawd, J. (1988): Household energy use in Zimbabwe, an analysis of consumption pattern and fuel choise, bibliographic citation, Energy for Rural Development in Zimbabwe.

Just, B., Hunt, F. and Ponce, L. B. (1998): Predictors of energy use by household in a rural area of the Philippines, Home Economics Research Journal, Vol. 18, no2. 
Mc clave, J. and sincich, T. (2006): Statistics, 10 Edition, Pearson Education, Inc. Pearson prentice Hall upper saddle River, New Jersey, U.S.A.

Sheile, C. Mc. (1994): Malaysian household electricity consumption, University of Calgary, Canada.

\title{
RURAL WOMEN'S PRACTICES FOR RATIONALIZING HOME ENERGY CONSUMPTION AND THEIR KNOWLEDGE ABOUT ADVANTAGES AND DISADVANTAGES OF USING TRADITIONAL AND NEW RESOURCES OF ENERGY IN SOME VILLAGES IN BEHIRA GOVERNORATE \\ Hassieb, Hayam M. A. \\ Agriculture Extension and Rural Development Research Institute, ARC.
}

\begin{abstract}
This research mainly aimed to study rural women's practices for rationalizing home energy consumption and their knowledge about advantages and disadvantages of using traditional and new resources of energy in some villages in Behira governorate. The study was carried out through achieving the following sub-goals:

1-Assess some characteristics of the respondents.

2-To define the respondents level of practices for rationalizing home energy consumption (electricity and gas).

3-Assess the respondents level of knowledge about advantages and disadvantages of using traditional and new resources of energy.

4-Assess the related relation between some independent variables and dependent variables.

Data were collected by questionnaire through personal interviews with a random sample consisted of 223 rural respondents percentages, frequencies and Pearson correlation were used in analyzing the data.

Data indicated the following results:

1-Most of the respondents had a high level of practices for rationalizing home electric energy consumption.

2-Low and medium level of practices for rationalizing home gas consumption were observed among most of respondents.

3-Low and medium level of knowledge about advantages and disadvantages of using traditional and new resources of energy were founded between the majority of respondents.

4-There were positive significant relation between respondents' educational level, husband educational level, number of machines, number of information resources and level of practices for rationalizing electric energy consumption, but negative significant relation between husband age and level of practices for rationalizing electric energy consumption.

5 -There were positive significant relation between educational level of respondents, educational level of husband, number of machines, number of information resources and level of practices for rationalizing gas
\end{abstract}


consumption, but negative significant relation between gas monthly cost and level of practices for rationalizing gas consumption.

6 -There were positive significant relation between educational level of respondents, educational level of husband job, number of machines, number of information resources and level of knowledge about advantages and disadvantages of using traditional and new resources of energy, but negative significant relation between respondents age, husband age, family size and level of knowledge about advantages and disadvantages of using traditional and new resources of energy.

كلية الزراعة - جامعة المنصورة كلية الزراعة - جامعة الإسكندرية

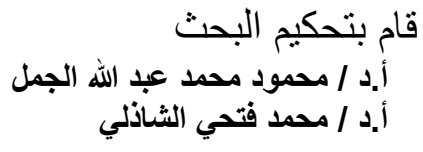

